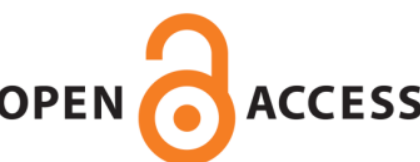

UWS Academic Portal

\title{
The effect of the branched-chain amino acids on the in-vitro activity of bovine
} intestinal alkaline phosphatase

Boyd, Gary William; Drew, Marion; Ward, Shannon; Baird, Marianne; Connaboy, Christopher; Graham, Scott Murray

Published in:

Applied Physiology, Nutrition, and Metabolism

DOI:

10.1139/apnm-2018-0449

Published: 01/06/2019

Document Version

Peer reviewed version

Link to publication on the UWS Academic Portal

Citation for published version (APA):

Boyd, G. W., Drew, M., Ward, S., Baird, M., Connaboy, C., \& Graham, S. M. (2019). The effect of the branchedchain amino acids on the in-vitro activity of bovine intestinal alkaline phosphatase. Applied Physiology, Nutrition, and Metabolism, 44(6), 632-636. https://doi.org/10.1139/apnm-2018-0449

\section{General rights}

Copyright and moral rights for the publications made accessible in the UWS Academic Portal are retained by the authors and/or other copyright owners and it is a condition of accessing publications that users recognise and abide by the legal requirements associated with these rights.

Take down policy

If you believe that this document breaches copyright please contact pure@uws.ac.uk providing details, and we will remove access to the work immediately and investigate your claim. 
Copyright and reuse of content

As of 2009, copyright of all articles in NRC Research Press journals remains with the authors.

Copyright of all articles published prior to 2009 is held by Canadian Science Publishing (operating as NRC Research Press) or its licensors.

No part of the NRC Research Press journals may be reproduced, stored, or transmitted in any form or by any means, without the written permission, obtainable through RightsLink, except as stated below or for those open access journals or articles administered under the terms of a Creative Commons license.

Under the Canadian Copyright Act, individuals may download or print single copies of articles for personal research or study. Any person may reproduce short excerpts ( $<100$ words) from articles in the journals for any purpose that respects the moral rights of authors, provided that the source is fully acknowledged. As a courtesy, the consent of the author(s) of such material should be obtained directly from the author(s).

Authorization to reproduce items other than for personal research or study, as stated above, may be obtained by clicking on the "Reprints \& Permissions" link in the Article Tools menu of the article in question or under license by Access Copyright.

The NRC Research Press journals also extend certain additional rights to authors.

For more information: http://www.nrcresearchpress.com/page/librarians/information/terms 
The effect of the branched-chain amino acids on the in-vitro activity of bovine intestinal alkaline phosphatase

Gary William Boyd ${ }^{1}$, Marion Drew ${ }^{1}$, Shannon Ward ${ }^{1}$, Marianne Baird ${ }^{2}$, Christopher Connaboy ${ }^{3}$ and Scott Murray Graham².

1- School of Science and Sport, University of the West of Scotland, Paisley, PA1 2BE, UK.

gary.boyd@uws.ac.uk, marion.drew@uws.ac.uk, B00234739@studentmail.uws.ac.uk (S. Ward).

2- School of Applied Sciences, Edinburgh Napier University, Edinburgh, EH11 4BN, UK.

M.Baird@napier.ac.uk, S.Graham3@napier.ac.uk

3- School of Health and Rehabilitation Sciences, University of Pittsburgh, Pittsburgh, PA 15260, USA. connaboy@pitt.edu

Corresponding author- Dr Gary Boyd, School of Science and sport, University of the West of Scotland, Paisley, PA1 2BE, UK., Tel. +44 141848 3128, gary.boyd@uws.ac.uk. 


\begin{abstract}
Branched-chain amino acids (BCAA) are used as nutritional support for patients with a range of conditions including liver cirrhosis and in-born errors of amino acid metabolism, and are commonly used "sports"/exercise supplements. The effects of the BCAA on the in-vitro activity of calf intestinal alkaline phosphatase (EC. 3.1.3.1) were studied. All three BCAA were found to be uncompetitive inhibitors of the enzyme with L-leucine being the most potent $\left(\mathrm{Ki}^{\prime}=24.9 \mathrm{mM}\right)$ and $\mathrm{L}$-valine, the least potent $\left(\mathrm{Ki}^{\prime}=37 \mathrm{mM}\right)$. Mixed BCAA are able to act in combination to inhibit the enzyme. Given the important role of intestinal alkaline phosphatase in gut homeostasis, these findings have potential implications for those taking high levels of BCAA as supplements.
\end{abstract}

Keywords; Intestinal Alkaline Phosphatase, Branched-chain amino acids, supplements, L-leucine, Lisoleucine, L-valine. 


\section{Introduction}

Intestinal alkaline phosphatase (IAP) has been demonstrated to play many important physiological roles (Lalles 2010) and IAP's interactions with the microbiota, the diet and the gut make it central to gut homeostasis (Estaki et al. 2014). IAP is involved in the absorption of dietary lipids across the gut wall (Narisawa et al. 2003; Eliakim et al. 1991; Tietze et al. 1992) and there is also evidence that IAP is involved in the regulation of surface $\mathrm{pH}$ in the duodenum (Akiba et al. 2007). In addition to these functions supporting the digestive activity of the gut, it has been demonstrated that IAP is able to help protect the body from pathogenic bacteria. IAP has been shown to limit bacterial passage from the lumen to the mesenteric lymph nodes (Goldberg et al. 2008) and is able to detoxify bacterial lipopolysaccharide (Beumer et al. 2003). These studies suggest that the interactions between the gut microbiota and IAP are crucial for intestinal health. It has been demonstrated that dietary factors affect IAP expression and activity; fasting decreases IAP expression/activity and this activity is restored when feeding recommences (Goldberg et al. 2008). Similarly, it has been demonstrated that levels of specific macronutrients, notably fats and proteins, in the diet can affect IAP (Alpers et al. 1995; Lynes et al. 2011; Montoya et al. 2006).

As essential amino acids, an adequate intake of BCAA is crucial to maintaining general health and supplementation with BCAA has been investigated in various clinical settings (Holecek 2018), including the treatment of cachexia in cancer patients (Choudry et al. 2006; Chen et al. 2015) and as nutritional support for patients with BCAA deficiencies (Joint Formulary Committee 2017-2018).

Protein and essential amino acid supplementation is also a common activity in sports/fitness settings. As part of this regime, BCAA supplementation has become commonplace and there has been much research on the possible ergogenic effects of leucine (Witard et al. 2016; Martin et al. 2017). Supplementation with 
leucine has a direct effect on the activation of the mammalian target of rapamycin (mTOR) pathway and the stimulation of muscle protein synthesis (MPS) (Foster and Fingar 2010; Reidy and Rasmussen 2016). These effects on MPS have been suggested to be dependent upon a number of factors such as nutrient timing strategies (Dickinson et al. 2014) and optimal dose (Churchward-Venne et al. 2014; Glynn et al. 2010; Mero 1999).

L-Leucine (L-Leu) has previously been reported to be an uncompetitive inhibitor of human AP (Hummer and Millan 1991; Hoylaerts et al. 1992). Given the important role of IAP in intestinal homeostasis and general health and the use of BCAA supplements, the present study sought to investigate the effects of the other BCAA and their combined effects on the in-vitro activity of IAP, using commercially available enzyme purified from calf intestine, as a model system. 


\section{Materials and methods}

Unless otherwise stated all materials were obtained from Sigma-Aldrich UK Itd and were the highest grades available. Enzyme was prepared in bulk at $1 \mathrm{mg} / \mathrm{ml}$ in $0.1 \mathrm{M}$ Glycine- $\mathrm{NaOH}$ buffer, pH9.8, $1 \mathrm{mM}$ $\mathrm{MgCl}_{2}$ and stored at $-20^{\circ} \mathrm{C}$ until use.

The activity of the enzyme was measured by following the hydrolysis of $p$-nitrophenol phosphate (pNPP) to $\mathrm{p}$-nitrophenol (pNP) at 400nm using a Jenway 7315 spectrophotometer. $0.068 \mathrm{M}$ Glycine-NaOH buffer, $\mathrm{pH} 9.8,0.68 \mathrm{mM} \mathrm{MgCl} 2$ was used and the velocity of the reaction at substrate (pNPP) concentrations ranging from $0.024-1.2 \mathrm{mM}$ were studied. Enzyme concentration in each assay was $0.08 \mathrm{mg} / \mathrm{ml}(\geq 10$ units $/ \mathrm{mg}$ ). The effects of the BCAA on the enzyme were examined by repeating the measurements of enzyme velocity in the presence of BCAA concentrations ranging from 0-20mM. All assays were performed in triplicate at $21 \pm 1^{\circ} \mathrm{C}$. The initial linear rate of the reaction was determined by linear regression of the experimental data and comparison to a pNP solution of known concentration $\left(2.875 \times 10^{-5} \mathrm{M}\right)$. The $\mathrm{K}_{\mathrm{m}}$ and $V_{\max }$ values of the enzyme were obtained by fitting the substrate concentration $v$ velocity data to the Michaelis curve by a non-linear least squares method. The $K_{m}$ and $V_{\max }$ values in the different experimental groups were analysed using a one-way ANOVA (not assuming equal variance). Where statistically significant differences were found, pairwise Welch's t-Tests using the Holm-Bonferroni correction were used poc hoc. The Ki' value of each inhibitor was determined using a secondary plot of inhibitor concentration $v$ the reciprocal of the observed $V_{\max }$ value, the $x$-axis intercept of this plot being equal to -Ki'. All data and statistical analyses were performed using "R" version 3.3.2 (R Core Team 2016). 


\section{Results}

\section{Effect of L-leucine on calf-IAP}

L-leucine decreased the $\mathrm{K}_{\mathrm{m}}$ of calf-IAP in a concentration dependent manner at concentrations ranging from 1-10mM (see Figure 1a). One-way ANOVA suggested a statistically significant difference between groups $\left(\mathrm{F}_{(3,15.13)}=39.139, \mathrm{p}=2.283 \times 10^{-7}\right)$. Pairwise $\mathrm{t}$-Tests using the Holm-Bonferroni correction established significant differences between all groups $(p<0.05)$.

Similarly, L-leucine also decreased the $\mathrm{V}_{\max }$ of calf-IAP (see Figure $1 \mathrm{~b}$ ) and one-way ANOVA suggested statistically significant differences between the groups $\left(F_{(3,15.135)}=17.195, p=3.6 \times 10^{-5}\right)$. Pairwise t-Tests using the Holm-Bonferroni correction suggested that this effect was only statistically significant at concentrations above $1 \mathrm{mM}$ L-leucine and that the difference between adjacent concentrations of the Lleucine was not statistically significant.

The $\mathrm{K}_{\mathrm{i}}^{\prime}$ of L-leucine was calculated to be $24.9 \mathrm{mM}$.

\section{Effect of L-Isoleucine on calf-IAP}

As was the case with L-leucine, L-isoleucine decreased the $\mathrm{K}_{m}$ of calf-IAP in a concentration dependent manner (see Figure 2a). One-way ANOVA suggested a statistically significant difference between groups 
$\left(\mathrm{F}_{(3,10.38)}=86.524, \mathrm{p}=1.22 \times 10^{-7}\right)$. Pairwise t-Tests using the Holm-Bonferroni correction established significant differences between all groups $(p<0.05)$.

L-isoleucine also had a statistically significant effect on the $V_{\max }$ of the enzyme (see Figure $2 b$ ), $(\mathrm{F})_{3}$ $\left.{ }_{10.99)}=7.395, p=0.0055\right)$. Pairwise t-Tests using the Holm-Bonferroni correction suggested that this effect was only statistically significant at concentrations above $1 \mathrm{mM}$ L-isoleucine and that the differences observed between the different treatment groups were not statistically significant.

The $\mathrm{K}_{\mathrm{i}}^{\prime}$ of L-Isoleucine was calculated to be $35.1 \mathrm{mM}$.

Effect of L-valine on calf-IAP

In agreement with the other members of the BCAA, L-valine decreased the $K_{m}$ of the enzyme (see Figure 3a). One-way ANOVA suggested statistically significant differences between the groups $\quad\left(F_{(3,14.96)}=\right.$ 51.05, $\left.p=4.3 \times 10^{-8}\right)$. Pairwise t-Tests using the Holm-Bonferroni correction established significant differences between all groups $(p<0.05)$.

L-valine also had a statistically significant effect on the $V_{\max }$ (see Figure $\left.3 b\right), F_{(3,15.51)}=14.513, p=9.05 \times 10^{-}$ $\left.{ }^{5}\right)$. Pairwise t-Tests using the Holm-Bonferroni correction suggested that this effect was only statistically significant at concentrations above $1 \mathrm{mM}$ L-valine.

The $\mathrm{K}_{\mathrm{i}}^{\prime}$ of L-valine was calculated to be $37 \mathrm{mM}$.

\section{Effect of mixed BCAAs on calf-IAP}

Those who take BCAA supplements often do so as mixtures, most commonly in the ratio of $2: 1: 1$, (Lleucine: L-isoleucine: L-valine). The effects of such a mixture of BCAA was examined in the present study, total BCAA concentrations ranged from 2-20mM. As observed with the individual amino acids, the BCAA 
mixture decreased the $K_{m}$ of the enzyme (see Figure $\left.4 a\right),\left(F_{(3,10.09)}=175.56, p=5.27 \times 10^{-9}\right)$. Pairwise $t$ Tests using the Holm-Bonferroni correction established significant differences between all groups $(p<0.05)$.

Similarly, the BCAA mixture decreased the $V_{\max }$ of the enzyme (see Figure $\left.4 b\right),\left(F_{(3,10.89)}=58.14, p=5.39 x\right.$ $\left.10^{-7}\right)$. Pairwise t-Tests using the Holm-Bonferroni correction established significant differences between all groups $(p<0.05)$.

The $\mathrm{K}_{\mathrm{i}}^{\prime}$ of the BCAA mixture was calculated to be $22.1 \mathrm{mM}$.

\section{Discussion}

There has been a longstanding clinical interest in the use of BCAA supplements to support patients with a range of conditions (Holecek 2018) and the BCAA are licensed in the UK for use as nutritional support in a number of clinical situations (Joint Formulary Committee 2017-18). The use of these supplements particularly in a "sports"/fitness context has also shown considerable growth in recent years (Close et al. 2016). The branched chain amino acids; L-leucine, L-isoleucine and L-valine are popular supplements reputed to stimulate MPS (Jackman et al. 2017), preserve lean muscle mass during weight loss strategies (Dudgeon et al. 2016), and to augment recovery after resistance training (Howatson et al. 2012). The current study sought to determine the in-vitro effects of these substances on IAP. The enzyme used in this study was the readily available calf-IAP but this is also a good model system for the human isozyme. Sequence alignment between human (NP_001622.2)(Kiffer-Moreira et al. 2014) and bovine (AAA30571.1)(Weissig et al. 1993) IAP suggested 77\% homogeneity between the proteins. In addition to this global similarity, the residues identified as being essential to AP activity in the human placental and 
germ-cell forms are conserved in the bovine intestinal isozyme (Kozlenkov et al. 2002). Moreover, the $\mathrm{K}_{\mathrm{m}}$ values observed in the present study were entirely consistent with previously reported values for human APs acting on p-NPP (Hoylaerts et al. 1992; Hummer and Millan 1991).

The effects of the BCAA on the kinetic parameters of calf-IAP were examined at concentrations between 1-10mM. We found that L-leucine produced a dose dependent decrease in both the $K_{m}$ (fig $1 \mathrm{a}$ ) and $V_{\max }$ (fig 1b) of the enzyme, only concentrations of L-leucine in excess of $1 \mathrm{mM}$ produced a statistically significant decrease in the $\mathrm{V}_{\max }$. These results suggest that L-leucine is an uncompetitive inhibitor of calfIAP with a $\mathrm{K}_{\mathrm{i}}^{\prime}$ of around $25 \mathrm{mM}$ and are in keeping with previous reports of the effect of L-leucine on AP (Hummer and Millan 1991; Hoylaerts et al. 1992). The effects of the other BCAA have not previously been reported; L-isoleucine also produced a dose dependent decrease in the $K_{m}$ (fig $2 a$ ) and $V_{\max }$ (fig $2 b$ ) of the enzyme suggesting that it is also an uncompetitive inhibitor, though rather less potent (the enzyme has a lower affinity for L-isoleucine) than L-leucine with a $\mathrm{K}_{\mathrm{i}}^{\prime}$ of $35 \mathrm{mM}$. Similarly L-valine was found to decrease both the $K_{m}$ (fig 3a) and $V_{\max }$ (fig $3 b$ ) of the enzyme and so would also appear to be an uncompetitive inhibitor with a $\mathrm{K}_{\mathrm{i}}^{\prime}(37 \mathrm{mM})$ similar to that of L-isoleucine. Given the structural similarity of the BCAA it would seem likely that they are binding to the same site and that this site is relatively specific for L-leucine. The use of a mixture of all three amino acids was studied, mimicking the situation where the BCAA are consumed in the ratio, 2:1:1. Total BCAA concentrations studied were $2-20 \mathrm{mM}$, again this produced a concentration dependent decrease in both the $K_{m}$ (fig $4 a$ ) and $V_{\max }$ (fig $4 b$ ) of the enzyme. In the case of the individual amino acids the lowest concentration studied $(1 \mathrm{mM})$ did not produce a statistically significant decrease in the $V_{\max }$ of the enzyme (figs $1 b, 2 b$ and $3 b$ ) but the higher concentrations did. When studying the mixture of all three amino acids the lowest concentration used was $2 \mathrm{mM}$ and this did produce a statistically significant decrease in the $\mathrm{V}_{\max }$, suggesting that the different BCAA may be able to act in combination to inhibit IAP. It seems likely that all BCAA bind to the same inhibitor site on the enzyme and that the L-isoleucine and L-valine may contribute to the inhibition mediated by the L-leucine. This is 
supported by the finding that the $K_{i}^{\prime}$ for the BCAA mixture was $22 \mathrm{mM}$, similar to the $K_{i}^{\prime}$ of leucine alone (24.9mM). In the present study, the inhibitory effects of the BCAA on IAP appears to have an upper limit. In all legs of the study, the maximum inhibition observed was around $30-40 \%$, regardless of the BCAA concentration ranges used $(1-10 \mathrm{mM}$ or $2-20 \mathrm{mM})$. Sports/fitness supplementation in humans could produce higher concentrations e.g., a $2 \mathrm{~g}$ dose taken with $100 \mathrm{ml}$ of $\mathrm{H}_{2} \mathrm{O}$ on an empty stomach would produce a gastric concentration of $\sim 105 \mathrm{mM}$. It is possible that such higher BCAA concentrations could produce greater inhibition of the enzyme as observed in previous studies of the effects of L-leucine on APs (Hoylaerts et al. 1992; Hummer and Millan 1991). However, this seems unlikely since the data from the present study suggest that the effects of the inhibitors are plateauing at the upper end of the concentration ranges used. This difference could reflect the fact that the intestinal form of AP is less sensitive to the inhibitory effects of the BCAA $\left(K_{i}^{\prime}\right.$ for L-leucine of $\left.24.9 \mathrm{mM}\right)$ than the placental $\left(K_{i}^{\prime}=9.2 \mathrm{mM}\right)$ or germ-cell forms $\left(\mathrm{K}_{\mathrm{i}}^{\prime}=0.54 \mathrm{mM}\right)$ used in the earlier studies (Hoylaerts et al. 1992).

\section{Conclusion}

All three of the branched-chain amino acids (BCAA) are uncompetitive inhibitors of calf-IAP. L-leucine was the most potent inhibitor studied $\left(\mathrm{K}_{\mathrm{i}}^{\prime}=24.9 \mathrm{mM}\right)$ with L-isoleucine and L-valine being noticeably less effective ( $\mathrm{K}_{\mathrm{i}}^{\prime}=35$ and $37 \mathrm{mM}$ respectively). Studies using a mixture of all three BCAA suggested that the amino acids were able to combine to inhibit the enzyme. Given the importance of IAP in gut homeostasis, these results have potential implications for those consuming high levels of BCAA as "sports"/fitness supplements.

\section{Conflicts of interest}

The authors have no conflicts of interest to report. 


\section{References}

Akiba, Y., Mizumori, M., Guth, P.H., Engel, E., Kaunitz, J.D. 2007. Duodenal brush border intestinal alkaline phosphatase activity affects bicarbonate secretion in rats. Am. J. Physiol. Gastrointest. Liver Physiol. 293: G1223-G1233. DOI: 10.1152/ajpgi.00313.2007. PMID:17916646.

Alpers, D.H., Zhang, Y., Ahnen, D.J. 1995. Synthesis and parallel secretion of rat intestinal alkaline phosphatase and a surfactant-like particle protein. Am. J. Physiol. 268: E1205-E1214.

DOI:10.1152/ajpendo.1995.268.6.E1205. PMID:7611397.

Beumer, C., Wulferink, M., Raaben, W., Fiechter, D., Brands, R., Seinen, W. 2003. Calf intestinal alkaline phosphatase, a novel therapeutic drug for lipopolysaccharide (LPS)-mediated disease, attenuates LPS toxicity in mice and piglets. J. Pharmacol. Exp. Ther. 307: 737-744. DOI:10.1124/jpet.103.056606.

PMID:12970380.

Chen, L., Chen, Y., Wang, X., Li, H., Zhang, H., Gong, J., et al. 2015. Efficacy and safety of oral branchedchain amino acid supplementation in patients undergoing interventions for hepatocellular carcinoma: a metaanalysis. Nutr. J. 14:67. DOI: 10.1186/s12937-015-0056-6. PMID:26155840.

Choudry, H.A., Pan, M., Karinch, A.M., Souba, W.W. (2006) Branched-chain amino acid-enriched nutritional support in surgical and cancer patients. J. Nutr. 136 (1 Suppl), 314S-318S. DOI:

10.1093/jn/136.1.314S. PMID:16365105.

Churchward-Venne, T.A., Breen, L., Di Donato, D.M., Hector, A.J., Mitchell, C.J., Moore, D.R. 2014. Leucine supplementation of a low-protein mixed macronutrient beverage enhances myofibrillar protein synthesis in young men: A double-blind, randomized trial1-3. American Journal of Clinical Nutrition, 99(2), 276-286. DOI: 10.3945/ajcn.113.068775. PMID:24284442. 
Close, G.L., Hamilton, D.L., Philip, A., Burke, L.M., Morton, J. P. 2016. New strategies in sport nutrition to increase exercise performance. Free Radic. Biol. Med. 98, 144-158. DOI:

10.1016/j.freeradbiomed.2016.01.016. PMID:26855422.

Dickinson, J.M., Gundermann, D.M., Walker, D.K., Reidy, P.T., Borack, M.S., Drummond, M.J., et al. 2014. Leucine-Enriched Amino Acid Ingestion after Resistance Exercise Prolongs Myofibrillar Protein Synthesis and Amino Acid Transporter Expression in Older Men. Journal of Nutrition, 144(11): 1694-1702. DOI: 10.3945/jn.114.198671. PMID:25332468.

Dudgeon, W.D., Kelley, E.P., Scheett, T.P. 2016. In a single-blind, matched group design: branched amino acid supplementation and resistance training maintains lean body mass during a caloric restricted diet. J. Int. Soc. Sports Nutr. 13(1): 1-10. DOI:10.1186/s12970-015-0112-9. PMID:26733764.

Eliakim, R., Mahmood, A., Alpers, D.H. 1991. Rat intestinal alkaline phosphatase secretion into lumen and serum is coordinately regulated. Biochim. Biophys. Acta, 1091: 1-8. PMID:1671644.

Estaki, M., DeCoffe, D., Gibson, D.L. 2014. Interplay between intestinal alkaline phosphatase, diet, gut microbes and immunity. World J. Gastroenterol. 20(42): 15650-6. DOI: 10.3748/wjg.v20.i42.15650. PMID:25400448.

Foster, K.G., Fingar, D.C. 2010. Mammalian Target of Rapamycin (mTOR): Conducting the Cellular Signalling Symphony. J. Biol. Chem. 285(19): 14071-14077. DOI: 10.1074/jbc.R109.094003. PMID:20231296.

Glynn, E.L., Fry, C.S., Drummond, M.J., Timmerman, K.L., Dhanani, S., Volpi, E., et al. 2010. Excess Leucine Intake Enhances Muscle Anabolic Signaling but Not Net Protein Anabolism in Young Men and Women. Journal of Nutrition, 140(11): 1970-1976. DOI: 10.3945/jn.110.127647. PMID:20844186. 
Goldberg, R.F., Austen, W.G., Zhang, X., Munene, G., Mostafa, G., Biswas, S., et al. 2008. Intestinal alkaline phosphatase is a gut mucosal defense factor maintained by enteral nutrition. Proc. Natl. Acad. Sci. USA. 105: 3551-3556. DOI: 10.1073/pnas.0712140105. PMID:18292227.

Holecek, M. 2018. Branched-chain amino acids in health and disease: metabolism, alterations in blood plasma, and as supplements. Nutrition and Metabolism, 15:33. DOI: 10.1186/s12986-018-0271-1. PMID:29755574.

Howatson, G., Hoad, H., Goodall, S., Tallent, J., Bell, P.G., French, D.N. 2012. Exercise-induced muscle damage is reduced in resistance-trained males by branched chain amino acids: a randomised doubleblind, placebo controlled study. J. Int. Soc. Sports Nutr. 9 (20): 1-7. DOI: 10.1186/1550-2783-9-20. PMID:22569039.

Hoylaerts, M.F., Manes, T., Millan, J.L. 1992. Molecular mechanism of uncompetitive inhibition of human placental and germ-cell alkaline phosphatase. Biochem. J. 286: 23-30. PMID:1520273.

Hummer, C., Millan, J.L. 1991. Gly429 is the major determinant of uncompetitive inhibition of human germ cell alkaline phosphatase by L-leucine. Biochem. J. 274: 91-95. PMID:2001256.

Jackman, S.R., Witard, O.C., Philip, A., Wallis, G.A., Baar, K., Tipton, K.D. 2017. Branched-chained amino acid ingestion stimulates muscle myofibrillar protein synthesis following resistance exercise in humans. Frontiers in Physiology, 8: 390. DOI: 10.3389/fphys.2017.00390. PMID:28638350.

Joint Formulary Committee. 2017-2018. British National Formulary (online) London: BMJ Group and Pharmaceutical Press http://www.bnf.nice.org.uk. [accessed on 7/8/18].

Kiffer-Moreira, T., Sheen, C.R., Gasque, K.C., Bolean, M., Ciancaglini, P., van Elsas, A., et al. 2014. Catalytic signature of a heat-stable, chimeric human alkaline phosphatase with therapeutic potential. PLoS ONE, 9(2), E89374. DOI: 10.1371/journal.pone.0089374. PMID:24586729. 
Kozlenkov, A., Manes, T., Hoylaerts, M.F., Millan, J.L. 2002. Function Assignment to Conserved Residues in Mammalian Alkaline Phosphatases. J. Biol. Chem. 277(25): 22992-22999. DOI:

10.1074/jbc.M202298200. PMID:11937510.

Lalles, J.P. 2010. Intestinal alkaline phosphatase: multiple biological roles in maintenance of intestinal homeostasis and modulation by diet. Nutrition Rev. 68(6): 323-332. DOI: 10.1111/j.1753-

4887.2010.00292.x. PMID:20536777.

Lynes, M., Narisawa, S., Millan, J.L., Widmaier, E.P. 2011. Interactions between CD36 and global intestinal alkaline phosphatase in mouse small intestine and effects of high-fat diet. Am. J. Physiol. Regul. Integr. Comp. Physiol. 301: R1738-R1747. DOI: 10.1152/ajpregu.00235.2011. PMID:21900644. Martin, N.R.W., Turner, M.C., Farrington, R., Player, D.J., Lewis, M.P. 2017. Leucine elicits myotube hypertrophy and enhances maximal contractile force in tissue engineered skeletal muscle in vitro. J. Cell. Physiol. 232(10): 2788-2797. DOI: 10.1002/jcp.25960. PMID:28409828.

Mero, A. 1999. Leucine Supplementation and Intensive Training. Sports Medicine, 27(6): 347-358. PMID:10418071.

Montoya, C.A., Leterme, P., Lalles, J.P. 2006. A protein-free diet alters small intestine architecture and digestive enzyme activites in rats. Reprod. Nutr. Dev. 46: 49-56. DOI: 10.1051/rnd:2005063. PMID:16438914.

Narisawa, S., Huang, L., Iwasaki, A., Hasegawa, H., Alpers, D.H., Millán, J.L. 2003. Accelerated fat absorption in intestinal alkaline phosphatase knockout mice. Mol. Cell. Biol. 23: 7525-7530. PMID:14560000.

R Core Team. 2016. R: A language and environment for statistical computing. R Foundation for Statistical Computing, Vienna, Austria. URL https://www.R-project.org/. 
Reidy, P., Rasmussen, B.B. 2016. Role of ingested amino acids and protein in the promotion of resistance exercise-induced muscle protein anabolism. Journal of Nutrition, 146(20): 155-183. DOI:

10.3945/jn.114.203208. PMID:26764320.

Tietze, C.C., Becich, M.J., Engle, M., Stenson, W.F., Mahmood, A., Eliakim, R., et al. 1992. Caco-2 cell transfection by rat intestinal alkaline phosphatase cDNA increases surfactant-like particles. Am. J. Physiol. Gastrointest. Liver Physiol. 263: G756-G766. DOI: 10.1152/ajpgi.1992.263.5.G756. PMID:1443151.

Weissig, H., Schildge, A., Hoylaerts, M.F., Iqbal, M., Millan, J.L. 1993. Cloning and expression of the bovine intestinal alkaline phosphatase gene: biochemical characterization of the recombinant enzyme. Biochem. J. 290(2): 503-508. PMID:8452539.

Witard, O.C., Wardle, S.L., Macnaughton, L.S, Tipton, K.D. 2016. Protein considerations for optimising skeletal muscle mass in healthy young and older adults. Nutrients, 8(4): 181. DOI: 10.3390/nu8040181. PMID:27023595.

\section{Figure captions}

Fig 1. The effect of L-leucine on intestinal alkaline phosphatase. The in-vitro activity of calf-IAP was measured in the presence of increasing concentrations of L-leucine $(0-10 \mathrm{mM})$ and the effects on the $\mathrm{K}_{\mathrm{m}}$ (A) and $V_{\max }(B)$ of the enzyme were determined $(n=8)$. Data presented as standard boxplots. Pairwise $t-$ tests using the Holm correction were used to determine statistically significant differences between the group means. 
Fig 2. The effect of L-isoleucine on intestinal alkaline phosphatase. The in-vitro activity of calf-IAP was measured in the presence of increasing concentrations of L-Isoleucine $(0-10 \mathrm{mM})$ and the effects on the $K_{m}(A)$ and $V_{\max }(B)$ of the enzyme were determined $(n=6)$. Data presented as standard boxplots. Pairwise t-tests using the Holm correction were used to determine statistically significant differences between the group means.

Fig 3. The effect of L-valine on intestinal alkaline phosphatase. The in-vitro activity of calf-IAP was measured in the presence of increasing concentrations of L-valine $(0-10 \mathrm{mM})$ and the effects on the $\mathrm{K}_{\mathrm{m}}$ (A) and $V_{\max }(B)$ of the enzyme were determined $(n=8)$. Data presented as standard boxplots. Pairwise ttests using the Holm correction were used to determine statistically significant differences between the group means.

Fig 4. The effect of mixed BCAA on intestinal alkaline phosphatase. The in-vitro activity of calf-IAP was measured in the presence of increasing concentrations of mixed BCAA (L-leu: L-isoleu: L-val; 2:1:1) (0$20 \mathrm{mM})$ and the effects on the $K_{m}(A)$ and $V_{\max }(B)$ of the enzyme were determined $(n=6)$. Data presented as standard boxplots. Pairwise t-tests using the Holm correction were used to determine statistically significant differences between the group means. 

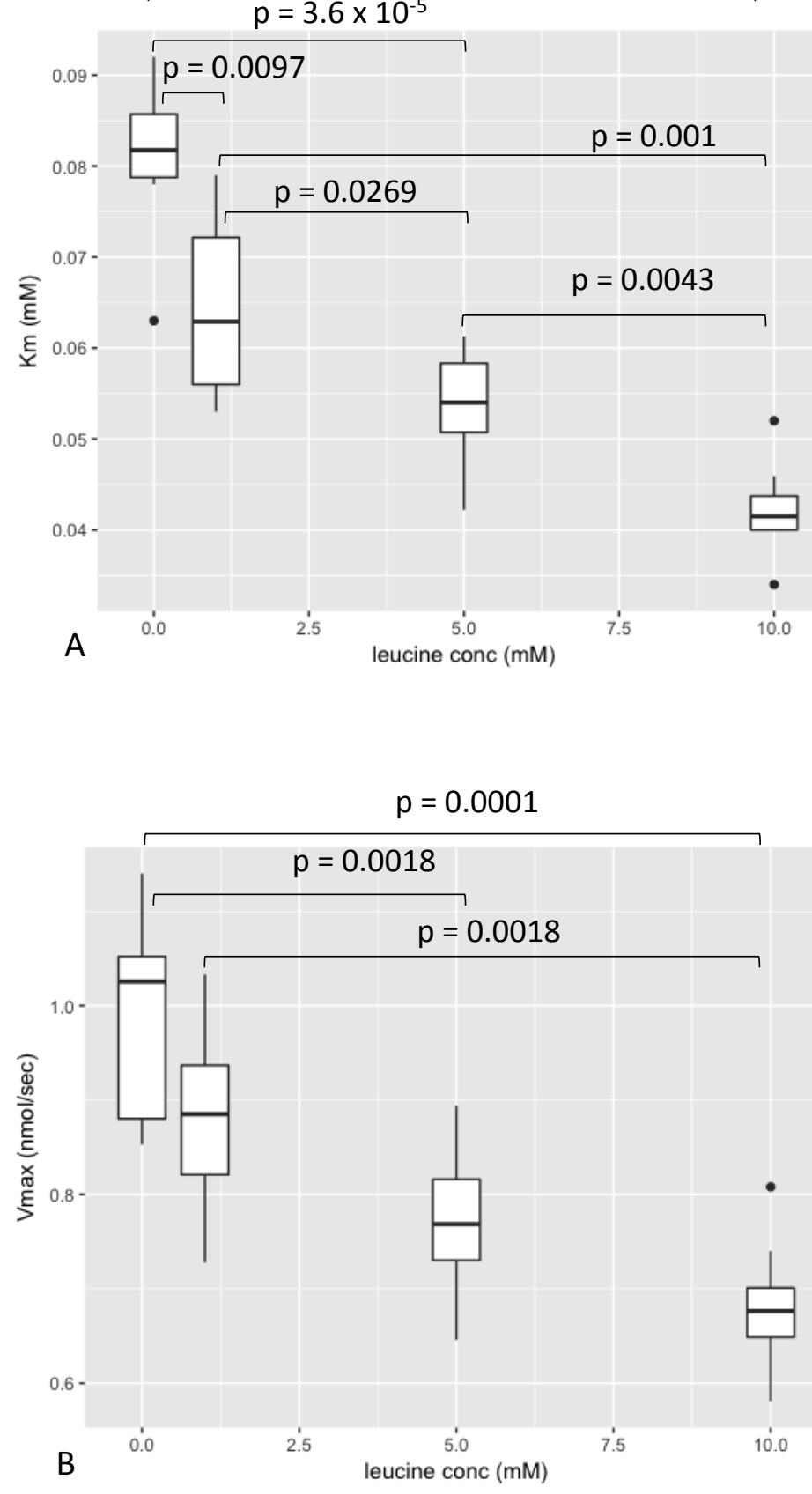

Fig. 1 


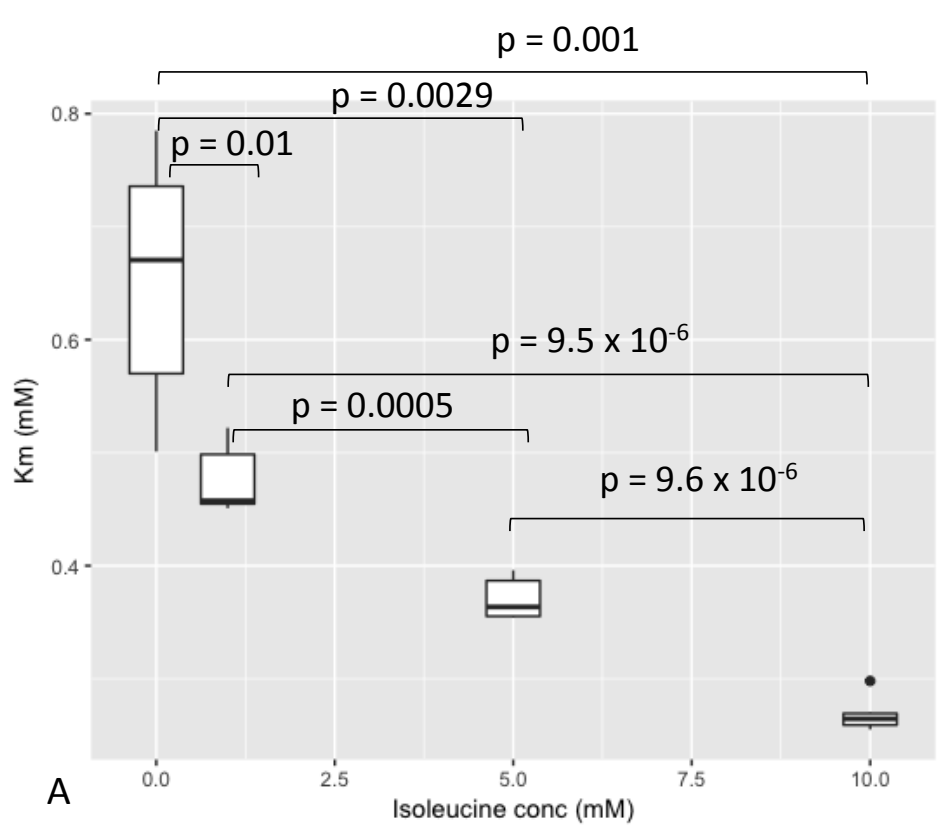

Page 18 of 20

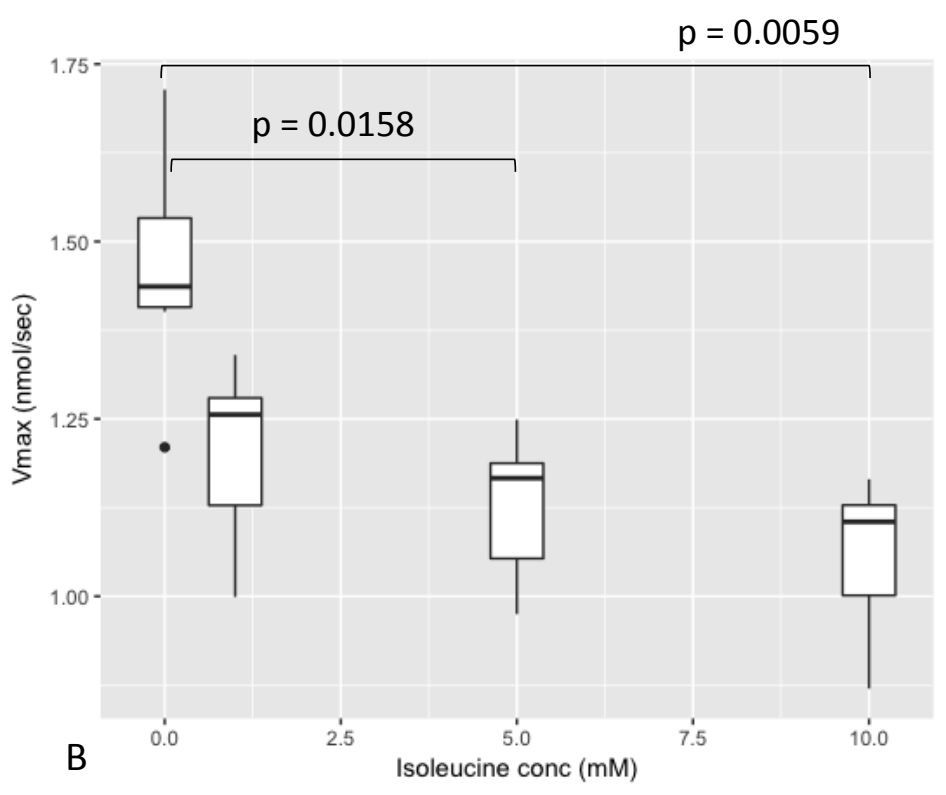

Fig. 2 

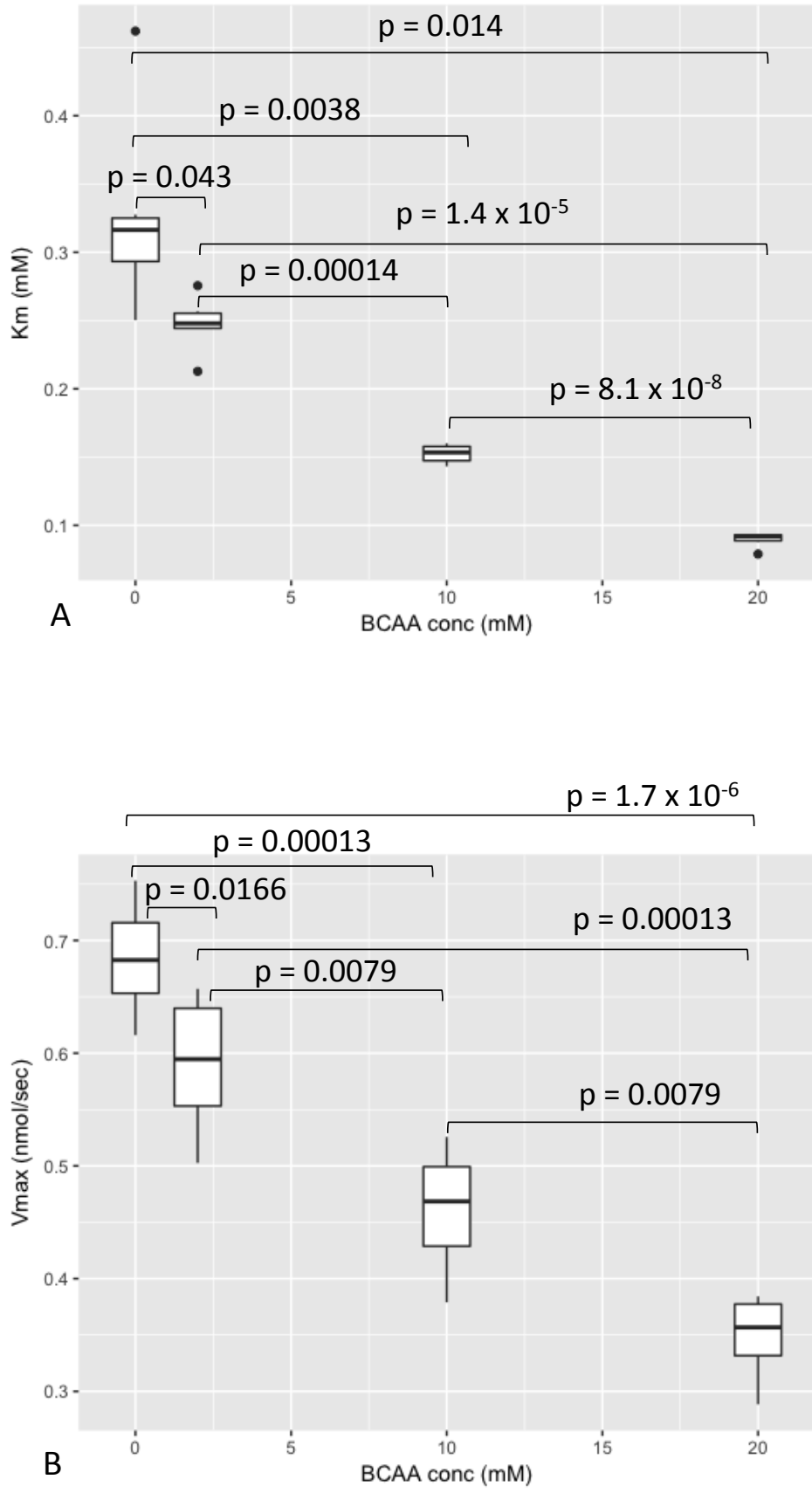

Fig.4 